\title{
A Genome Resource for the Apple Powdery Mildew Pathogen Podosphaera leucotricha
}

\author{
Lederson Gañán, ${ }^{1,2}$ Richard Allen White III, ${ }^{2,3,4}$ Maren L. Friesen, ${ }^{2,5}$ Tobin L. Peever, ${ }^{2}$ and \\ Achour Amiri, $1,+$ \\ ${ }^{1}$ Washington State University, Tree Fruit Research and Extension Center, Wenatchee, WA, U.S.A. \\ ${ }^{2}$ Washington State University, Department of Plant Pathology, Pullman, WA, U.S.A. \\ ${ }^{3}$ RAW Molecular Systems (RMS) LLC, Spokane, WA, U.S.A. \\ ${ }^{4}$ Australian Centre for Astrobiology, University of New South Wales, Sydney, NSW, Australia \\ ${ }^{5}$ Washington State University, Department of Crop and Soil Sciences, Pullman, WA, U.S.A.
}

\begin{abstract}
Powdery mildew, caused by Podosphaera leucotricha, is an economically important disease of apple and pear trees. A single monoconidial strain (PuE-3) of this biotrophic fungus was used to extract DNA for Illumina sequencing. Data were assembled to form a draft genome of $43.8 \mathrm{Mb}$ consisting of 8,921 contigs, 9,372 predicted genes, and $96.1 \%$ of complete benchmarking universal single copy orthologs (BUSCOs). This is the first reported genome sequence of $P$. leucotricha that will enable studies of the population biology, epidemiology, and fungicide resistance of this pathogen. Furthermore, this resource will be fundamental to uncover the genetic and molecular mechanisms of the apple-powdery mildew interaction, and support future pome fruit breeding efforts.
\end{abstract}

\section{Genome Announcement}

Powdery mildew, caused by Podosphaera leucotricha (Ellis \& Everh.) E. S. Salmon, is one of the most important and widespread diseases of cultivated apple (Malus $\times$ domestica) and pear (Pyrus spp.). Chronic effects of powdery mildew on tree vigor, especially in highly susceptible cultivars, can be detrimental to the profitability of orchards and nurseries (Butt et al. 1983; Serdani et al. 2005; Yoder 2000). Although young leaves are the most susceptible organs, powdery mildew infections also occur in blossoms and fruits, thus reducing crop yield and fruit market value because of fruit russet symptoms (Spotts 1984; Yoder 2000). Besides apple and pear, Podosphaera leucotricha has been reported from other host members of the Rosaceae family including peach (Prunus persica) (Jankovics et al. 2011), the African cherry tree (Prunus africana) (Mwanza et al. 2001), and ornamental photinias (Photinia spp.) (Garibaldi et al. 2005; Liang et al. 2012).

The biotrophic nature of Podosphaera leucotricha hinders research on the biology, genetic diversity, and host-pathogen interactions, which remain poorly understood (Amiri and Gañán 2019). Genetic and genomic approaches might overcome these limitations and help unravel some of the many unanswered questions. Despite the economic importance of powdery mildew on apple and pear crops, only 52 nucleotide sequences, all shorter than 1,600 bp, are publicly available in the NCBI database currently. Compared with other powdery mildew fungi, such as Blumeria graminis f. sp. tritici, B. graminis f. sp. hordei, and Erysiphe necator, genetic sequence resources available for Podosphaera leucotricha are much more limited. To overcome this limitation, we undertook a whole-genome shotgun sequencing approach to support the development of research studies on this significant plant parasite.

${ }^{\dagger}$ Corresponding author: A. Amiri; a.amiri@wsu.edu

The author(s) declare no conflict of interest.

Accepted for publication 3 June 2020.

\section{Funding}

This work was supported by the Department of Plant Pathology, College of Agricultural, Human, and Natural Resource Sciences, Agricultural Research Center, Hatch Project WNP0555, Washington State University, Pullman; the Washington State University Blanket Research Grant 3661-7905; and a Mike and Kathy Hambelton fellowship 3616-9837. The first author was supported by a Fulbright-Minciencias Scholarship.

\section{Keywords}

biotrophic, mycology, pome fruit, whole-genome shotgun sequencing 
Table 1. Podosphaera leucotricha draft genome assembly summary

\begin{tabular}{|c|c|}
\hline Genome assembly feature & Value \\
\hline Total length (bp) & $43,868,508$ \\
\hline Number of contigs $\geq 1,000 \mathrm{bp}$ & 8,921 \\
\hline Size of largest contig (bp) & 60,133 \\
\hline Contig $\mathrm{N}_{50}(\mathrm{bp})$ & 8,371 \\
\hline Contig $N_{90}(b p)$ & 1,921 \\
\hline GC content $(\%)$ & 43.69 \\
\hline BUSCO complete (\%) & 96.1 \\
\hline BUSCO duplicated (\%) & 0.4 \\
\hline BUSCO fragmented (\%) & 1.7 \\
\hline Number of predicted genes & 9,372 \\
\hline Interspersed repeat content (\%) & 77.8 \\
\hline Genome accession & JAATOF000000000 \\
\hline Version accession & JAATOF010000000 \\
\hline
\end{tabular}

The monoconidial strain PuE-3 of Podosphaera leucotricha was isolated from infected leaves of apple ('Golden Delicious' $\times$ 'White Angel') plantlets maintained in a growth chamber at Washington State University, Pullman, WA. Podosphaera leucotricha PuE-3 was grown and maintained on detached leaves from in vitro-propagated plantlets of apple genotype 02O3R5-75 (Wan and Fazio 2011). Conidia were collected from 14-day-old colonies using sterile acupuncture needles, followed by genomic DNA isolation using the Omniprep for fungi kit (G-Biosciences, St. Louis, MO), according to the manufacturer's protocol. A partial sequence of the internal transcribed spacer (ITS) region of ribosomal DNA was amplified using the primer pair ITS 5/ITS 4 (White et al. 1990). Results from a NCBI-BLASTn search revealed that the sequence obtained was $99 \%$ identical to the voucher specimen BPI 878262 of Podosphaera leucotricha (GenBank accession EU148597), thus confirming the identity of the PuE-3 strain. Genomic DNA was processed using KAPA Hyper Prep Kit (Kapa Biosystems, Wilmington, MA) to construct a paired-end library, which was then sequenced ( $2 \times 150$ bp) using the NextSeq 550 system (Illumina,San Diego, CA) at RTL Genomics (Lubbock, TX), producing a total of $50,255,101$ read pairs. Genome data were filtered using the ATLAS framework (White et al. 2017a) with a custom database containing potential contaminants including human, apple, phiX, Pseudomonas spp., and other members of the phyllosphere microbiome. Local and global alignments were performed using Bowtie 2 (Langmead and Salzberg 2012), with the verysensitive option, and then parsed using samtools and bbduk (part of bbmap). Finally, the filtered data were trimmed using bbduk and assembled in MEGAHIT (Li et al. 2015). k-mer lengths were preassessed for step length for MEGAHIT assembly using MerCat (White et al. 2017b).

Assembly of the sequenced reads yielded a draft genome of $43,868,508$ bp in 8,921 contigs $\left(\geq 1,000 \mathrm{bp}\right.$ ) with an $\mathrm{N}_{50}$ value of 8,371 and $\mathrm{GC}$ content of $43.7 \%$ (Table 1). Gene prediction and annotation was performed using the Genome Sequence Annotation Server (GenSAS 6.0) (Humann et al. 2019), following an eukaryotic annotation process. Repeat sequences were identified and masked using a combination of de novo and homology-based approaches. A de novo prediction of repetitive elements was performed using RepeatModeler v1.0.11, and the resulting library was inputted into RepeatMasker v4.0.5 (http://www.repeatmasker.org). Overall, $77.8 \%$ of the Podosphaera leucotricha PuE-3 genome was made of interspersed repeat elements and $0.1 \%$ of simple repeats. Protein-coding genes were predicted using a combination of $a b$ initio gene prediction using GenMark-ES (Ter-Hovhannisyan et al. 2008), followed by a gene model refinement with the tool EvidenceModeler (Haas et al. 2008). A total of 9,372 putative protein-coding genes were identified, of which 7,223 contained PFAM domains annotated by InterProScan v5.29-68.0 (Jones et al. 2014). Genome completeness analysis was estimated based on evolutionarily-informed expectations of gene content using the Universal Single-Copy Ortholog tool BUSCO v3 (Waterhouse et al. 2018; Simão et al. 2015). Benchmarking universal single copy ortholog (BUSCO) results reported 1,264 complete BUSCOs (C: $96.1 \%$ ) of a total of 1,315 core genes of the Ascomycota_odb9 lineage data set.

This draft genome sequence of Podosphaera leucotricha PuE-3 represents the first genome resource available for any powdery mildew fungus infecting economically important members of the family Rosaceae. This resource provides new data that will accelerate the development of molecular tools needed to conduct population biology and epidemiology studies of Podosphaera leucotricha. The newly developed genomic sequences can also be used as a 
reference for future genomic and transcriptomic studies in Podosphaera leucotricha. Specifically, these data will be useful for uncovering Podosphaera leucotricha effector genes involved in the host-pathogen interactions, assist future pome fruit breeding efforts, and provide insights into the evolution of powdery mildew fungi.

This whole genome shotgun project has been deposited at DDBJ/ENA/GenBank under accession JAATOF000000000 (BioProject number PRJNA562291). In this manuscript, we describe the version JAATOF010000000. Raw reads from the Illumina sequencing are available in the NCBI Sequence Read Archive under the accession SRR11471384. A voucher specimen of Podosphaera leucotricha PuE-3 was deposited in the Washington State University, Charles Gardner Shaw Mycological Herbarium (WSP), under accession number WSP73997, and the partial sequence of the ITS region, used for identity confirmation, was deposited in GenBank under accession MT180425. Assembly code is available on GitHub (https:// github.com/raw937/pleucotricha_mildew), and other data files mentioned herein are stored and publicly accessible in the Open Science Framework database (https://osf.io/reh8b).

\section{Acknowledgments}

We thank the Plant Genetic Resources Unit of USDA-ARS NEA for providing the rootstock research line 02O3R5-75 under the Material Transfer Agreement 15780.

\section{Literature Cited}

Amiri, A., and Gañán, L. 2019. Powdery mildew: Biology, epidemiology, and management of Podosphaera spp. of tree fruit. Pages 21-38 in: Burleigh Dodds Series in Agricultural Science. Burleigh Dodds Science Publishing, Cambridge, U.K.

Butt, D. J., Martin, K. M., and Swait, A. J. J. 1983. Apple powdery mildew: Damage, loss and economic injury level. Page 118 in: Proceedings of the 10th International Congress of Plant Protection, Brighton, U.K.

Garibaldi, A., Gilardi, G., and Gullino, M. L. 2005. First report of powdery mildew caused by Podosphaera leucotricha on Photinia fraserii in Italy. Plant Dis. 89:1362.

Haas, B. J., Salzberg, S. L., Zhu, W., Pertea, M., Allen, J. E., Orvis, J., White, O., Buell, C. R., and Wortman, J. R. 2008. Automated eukaryotic gene structure annotation using EVidenceModeler and the program to assemble spliced alignments. Genome Biol. 9:R7.

Humann, J. L., Lee, T., Ficklin, S., and Main, D. 2019. Structural and functional annotation of eukaryotic genomes with GenSAS. Pages 29-51 in: Gene Prediction: Methods and Protocols, Methods in Molecular Biology. M. Kollmar, ed. Springer, New York.

Jankovics, T., Dolovac, N., Bulajić, A., Krstić, B., Pascal, T., Bardin, M., Nicot, P. C., and Kiss, L. 2011. Peach rusty spot is caused by the apple powdery mildew fungus, Podosphaera leucotricha. Plant Dis. 95:719-724.

Jones, P., Binns, D., Chang, H.-Y., Fraser, M., Li, W., McAnulla, C., McWilliam, H., Maslen, J., Mitchell, A., Nuka, G., Pesseat, S., Quinn, A. F., Sangrador-Vegas, A., Scheremetjew, M., Yong, S.-Y., Lopez, R., and Hunter, S. 2014. InterProScan 5: Genome-scale protein function classification. Bioinformatics 30:1236-1240.

Langmead, B., and Salzberg, S. L. 2012. Fast gapped-read alignment with Bowtie 2. Nat. Methods 9:357-359.

Li, D., Liu, C.-M., Luo, R., Sadakane, K., and Lam, T.-W. 2015. MEGAHIT: An ultra-fast single-node solution for large and complex metagenomics assembly via succinct de Bruijn graph. Bioinformatics 31:1674-1676.

Liang, C., Xing, H. H., Cho, S. E., and Shin, H. D. 2012. First report of powdery mildew caused by Podosphaera leucotricha on Photinia serrulata in China. Plant Dis. 96: 1695.
Mwanza, E. J. M., Waithaka, S. K., and Simons, S. A. 2001. First report of powdery mildew caused by Podosphaera leucotricha on Prunus africana in Kenya. Plant Dis. 85:1285.

Serdani, M., Spotts, R. A., Calabro, J. M., and Postman, J. D. 2005. Powdery mildew resistance in Pyrus germplasm. Acta Hortic.: 609-613.

Simão, F. A., Waterhouse, R. M., Ioannidis, P., Kriventseva, E. V., and Zdobnov, E. M. 2015. BUSCO: Assessing genome assembly and annotation completeness with single-copy orthologs. Bioinformatics 31:3210-3212.

Spotts, R. A. 1984. Infection of Anjou pear fruit by Podosphaera leucotricha. Plant Dis. 68:857-859.

Ter-Hovhannisyan, V., Lomsadze, A., Chernoff, Y. O., and Borodovsky, M. 2008. Gene prediction in novel fungal genomes using an ab initio algorithm with unsupervised training. Genome Res. 18:1979-1990.

Wan, Y., and Fazio, G. 2011. Confirmation by QTL mapping of the Malus robusta ('Robusta5') derived powdery mildew resistance gene Pl1. Acta Hortic. 903:95-99.

Waterhouse, R. M., Seppey, M., Simão, F. A., Manni, M., Ioannidis, P., Klioutchnikov, G., Kriventseva, E. V., and Zdobnov, E. M. 2018. BUSCO applications from quality assessments to gene prediction and phylogenomics. Mol. Biol. Evol. 35:543-548.

White, R. A., III, Brown, J., Colby, S., Overall, C. C., Lee, J.-Y., Zucker, J., Glaesemann, K. R., Jansson, C., and Jansson, J. K. 2017a. ATLAS (Automatic Tool for Local Assembly Structures)-A comprehensive infrastructure for assembly, annotation, and genomic binning of metagenomic and metatranscriptomic data. PeerJ Preprints 5:e2843v1.

White, R. A., III, Panyala, A., Glass, K., Colby, S., Glaesemann, K. R., Jansson, C., and Jansson, J. K. 2017b. MerCat: A versatile k-mer counter and diversity estimator for database-independent property analysis obtained from metagenomic and/or metatranscriptomic sequencing data. PeerJ Preprints 5:e2825v1.

White, T. J., Bruns, T., Lee, S., and Taylor, J. 1990. Amplification and direct sequencing of fungal ribosomal RNA genes for phylogenetics. Pages 315-322 in: PCR Protocols: A Guide to Methods and Applications. Academic Press, New York.

Yoder, K. S. 2000. Effect of powdery mildew on apple yield and economic benefits of its management in Virginia. Plant Dis. 84:1171-1176. 